\title{
Editorial View
}

$t$ is indeed a pleasure to bring out yet another issue of the Nepal Journal of Dermatology, Venereology \& Leprology (NJDVL) by our team of dedicated and deligent doctors. The journal has been an official organ of the Society of Dermatologist, Venereolgist and Leprologist of Nepal(SODVELON) and over the years has helped in the dissemination and sharing of scientific dermatological information among doctors across the country and beyond since its very inception.

Like every year, we have attempted to incorporate scientific information appropriate to the context of the region, through original research articles and case reports. It was quite difficult for us to bring out the last issue in time due to various unavoidable circumstances including the massive earthquake that devasted us in heart and soul. This year however we have tried to rise beyond our dreams and expectations and tried to bring out this issue in time.

Every effort has been made to make this journal seen and read by a large community. No stones has been left unturned to get international affiliation and in getting the journal indexed. The editorial board has been working hard to improve the standard of the journal as well as working on making it more publicly visible and accountable. I and the entire editorial team expresses sincere thanks to all the contributors, who helped us by providing useful manuscripts for this journal. We would also like to express our sincere gratitude and thanks to the international and national advisors of the editorial board, whose advice and guidance has been invaluable.

Lastly, in spite of every effort, this issue still might have various shortcomings and we welcome your opinions and comments regarding the journal. Your valuable response $\&$ suggestions will surely help for further improvements in bringing out the subsequent issues we can all be proud of.

\author{
Dr. Sabina Bhattarai \\ Editor-in-Chief \\ NJDVL, 2016
}

